\title{
Magneto Dielectric-Laden Miniaturized Wideband Meander Line Antenna for Mobile Devices
}

\author{
Bancha Luadang $\mathbb{D},{ }^{1}$ Rewat Senathong, ${ }^{2}$ and Chuwong Phongcharoenpanich $\mathbb{D}^{2}$ \\ ${ }^{1}$ Department of Instrumentation Engineering, Faculty of Engineering, Rajamangala University of Technology Rattanakosin, \\ Salaya, Thailand \\ ${ }^{2}$ Department of Telecommunications Engineering, Faculty of Engineering, King Mongkut's Institute of Technology Ladkrabang, \\ Bangkok, Thailand \\ Correspondence should be addressed to Bancha Luadang; bancha.lua@rmutr.ac.th
}

Received 1 March 2018; Revised 20 May 2018; Accepted 26 May 2018; Published 5 July 2018

Academic Editor: Paolo Baccarelli

Copyright (c) 2018 Bancha Luadang et al. This is an open access article distributed under the Creative Commons Attribution License, which permits unrestricted use, distribution, and reproduction in any medium, provided the original work is properly cited.

\begin{abstract}
This research presents a miniaturized wideband meander line antenna (MLA) using a magneto dielectric (MD) material for mobile device applications. The proposed MLA attached the lower and upper ground planes of the folder-type chassis, connected electrically by grounding strip. The MD material (ECCOSORB MF-124) was subsequently loaded onto the coupling element area of the MLA. The MD-laden MLA was ultracompact $(10 \mathrm{~mm} \times 25 \mathrm{~mm} \times 1 \mathrm{~mm})$, with the electrical size of $0.015 \lambda \times 0.039 \lambda \times 0.0015 \lambda$ at $470 \mathrm{MHz}$. The surface current distribution was simulated to determine the optimal parameters of the MD-laden MLA. To verify, a prototype antenna was fabricated and the experiments were performed. The measured impedance bandwidth $\left(\left|S_{11}\right|<-6 \mathrm{~dB}\right)$ covered the frequency range of $467-1012 \mathrm{MHz}(73.6 \%)$, with an omnidirectional radiation pattern. The radiation efficiency was in excess of $90 \%$, rendering it suitable for the DVB-H/ LTE13/GSM850/900 applications.
\end{abstract}

\section{Introduction}

The recent decades have witnessed an accelerated development of wireless devices and mobile wireless communication devices to cater to diverse needs of consumers. Modern mobile devices are thus becoming more compact and more affordable, with attractive appearance and smart functions. As a result, the newer generation of mobile communication devices requires smaller and more cost-effective antennas.

The mobile devices or handsets that simultaneously operate in the DVB-H $(470-862 \mathrm{MHz}), \mathrm{LTE} 13(746-787 \mathrm{MHz})$, and GSM850/900 (824-894 MHz/880-960 MHz) bands present an implementation challenge of integrating an internal antenna in the compact device. The challenge multiplies for the lower-end frequency $(470 \mathrm{MHz})$ whose free-space wavelength is substantially large $\left(\lambda_{0}=64 \mathrm{~cm}\right)$ and thus the sizable device antenna.

Recent research has proposed several types of miniaturized antennas for mobile applications. In [1], a modified earpiece cord was proposed as a wideband DVB-H antenna, whereby the cord was wound into a high-impedance radio frequency (RF) choke at one-quarter wavelength distance from the handset connection. In addition, a four-feed antenna scheme was proposed to generate nine frequency bands for mobile phones; however, the implementation of the scheme required the impedance matching circuit, resulting in the costly complex structure [2]. In [3-5], the frequency-tunable antennas were realized by applying DC bias voltage to an active component. The antennas achieved the resonant frequency across the desired frequency bands. The antennas, however, required the tuning circuits to realize the resonant frequency, contributing to the low antenna gain due to the interfacial component loss.

A novel modified compact monopole DVB-H antenna was proposed by extending the feeding line, which was placed atop the ground plane, and modifying the antenna element line. Nevertheless, the antenna usefulness was restricted to the DVB-H application [6]. In [7], a DVB-H 
antenna was realized by combining a coupling element and a folder-type mobile phone chassis. The antenna utilized the chassis as a main radiator, and the compact coupling element was loaded on a ferrite without a matching circuit. The impedance bandwidth, however, satisfies only the DVB-H (468-719 MHz) requirement. In [8], an internal antenna for mobile handsets could achieve a very wide impedance bandwidth, covering the LTE13 (746-787 MHz), GSM850 $(824-894 \mathrm{MHz})$, and GSM900 (880-960 MHz) bands. It, nevertheless, partially covered the lower-end frequency for the DVB-H application $(470 \mathrm{MHz})$. Theoretically, an antenna should have as low reflection coefficient as possible. However, $\left|S_{11}\right|$ of less than $-10 \mathrm{~dB}$ is practically hard to be obtained for small antenna. Some antennas in the previous works can accept a $-4.5 \mathrm{~dB}$ reflection level [9]. From open literature, most mobile device antennas are designed using $\left|S_{11}\right|<-6 \mathrm{~dB}$ criteria $[1,3,4,7-10]$. In [10], the authors proposed a planar meander monopole antenna for multiband wireless communication using parasitic strips and a sleeve feed. The antenna achieved a wide impedance bandwidth (101.7\%) from 440 to $1350 \mathrm{MHz}$ (voltage standing wave ratio $<3)$, satisfying the DVB-H/LTE13/GSM850/900 requirements. Nonetheless, the antenna radiator suffered from the bulkiness $(65 \mathrm{~mm} \times 44 \mathrm{~mm})$, rendering it unsuitable for the compact application.

In order to obtain a broad impedance bandwidth while maintaining the compact size of a miniaturized antenna, studies have introduced the magneto dielectric (MD) materials to the antennas [11-18]. The antenna size reduction and bandwidth improvement were achieved using the MD materials with moderate permittivity and permeability. In [11], the impedance bandwidth of a printed antenna over a magneto dielectric substrate of thickness $(t)$ can be approximated by

$$
\mathrm{BW}=\frac{96 \sqrt{(\mu / \varepsilon)} \cdot\left(t / \lambda_{0}\right)}{\sqrt{2}(4+17 \sqrt{\mu \varepsilon})}
$$

In (1), the miniaturization is governed by a factor that suppresses the wavelength by a factor of $\sqrt{\mu \varepsilon}$. The relationship between the permittivity and permeability of an MD material and the resonant wavelength is given by

$$
\lambda_{\text {resonant }}=\frac{\lambda_{0}}{\sqrt{\mu \varepsilon}},
$$

where $\lambda_{0}$ is the free space wavelength. The impedance bandwidth of the antenna can be enhanced by a factor of $\sqrt{\mu / \varepsilon},(\mu>\varepsilon)$.

Specifically, this research proposes a miniaturized wideband meander line antenna (MLA) using a magneto dielectric (MD) material for mobile device applications. The MD-laden MLA could achieve a substantial size reduction, with the physical dimension of $10 \mathrm{~mm} \times 25 \mathrm{~mm} \times 1 \mathrm{~mm}$ and the electrical size of $0.015 \lambda \times 0.039 \lambda \times 0.0015 \lambda$ at $470 \mathrm{MHz}$. Furthermore, the antenna achieves a wide impedance bandwidth $\left(\left|S_{11}\right|<-6 \mathrm{~dB}\right)$ from $467-1012 \mathrm{MHz}$, covering the target operating band $(470-960 \mathrm{MHz})$, and a high radiation

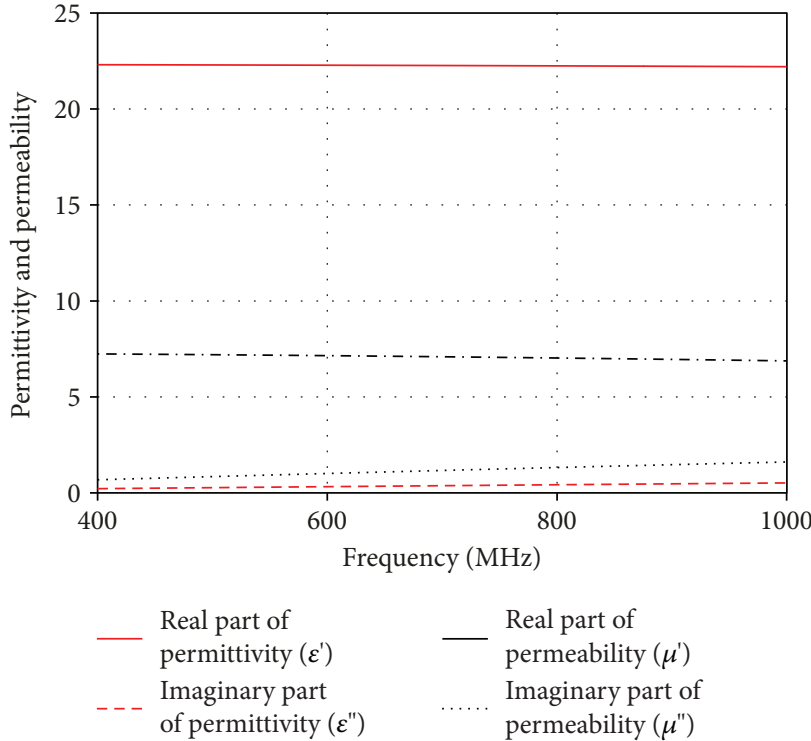

FIGURE 1: Simulated relative permittivity and permeability of the experimental magneto dielectric substrate (ECCOSORB MF-124) relative to frequency $(400-1000 \mathrm{MHz})$.

TABLE 1: The simulated relative permittivity and permeability of ECCOSORB Mf-124 for various operating frequencies $(470-960 \mathrm{MHz})$.

\begin{tabular}{lcccc}
\hline Operating band/(MHz) & $\varepsilon^{\prime}$ & $\tan \delta_{\varepsilon}$ & $\mu^{\prime}$ & $\tan \delta_{\mu}$ \\
\hline DVB-H/470 & 22.30 & 0.011 & 7.22 & 0.111 \\
DVB-H/666 & 22.27 & 0.016 & 7.12 & 0.157 \\
DVB-H/862 & 22.25 & 0.018 & 7.05 & 0.180 \\
LTE13/766 & 22.24 & 0.020 & 6.99 & 0.199 \\
GSM/850 & 22.23 & 0.020 & 6.98 & 0.202 \\
GSM/900 & 22.22 & 0.021 & 6.96 & 0.211 \\
\hline
\end{tabular}

efficiency in excess of $90 \%$. The MD-laden MLA is thus suitable for the DVB-H/LTE13/GSM850/900 applications.

The organization of the research is as follows: Section 1 is the introduction. Section 2 details the design and evolution of the proposed antenna. Section 3 deals with the parametric study of the antenna, and Section 4 discusses the antenna prototype and experimental results. The concluding remarks are provided in Section 5.

\section{Design of the Proposed Antenna}

2.1. Magneto Dielectric (MD). MD materials are synthesized materials that are normally realized by an accurate material property characterization method. Specifically, in an MDloaded antenna, its response is governed by the frequencydependent relative permittivity and permeability of the MD material. Both relative permittivity and permeability are complex numbers [19-24], which can be expressed as

$$
\begin{aligned}
& \varepsilon_{r}=\varepsilon^{\prime}-j \varepsilon^{\prime \prime}, \\
& \mu_{r}=\mu^{\prime}-j \mu^{\prime \prime} .
\end{aligned}
$$




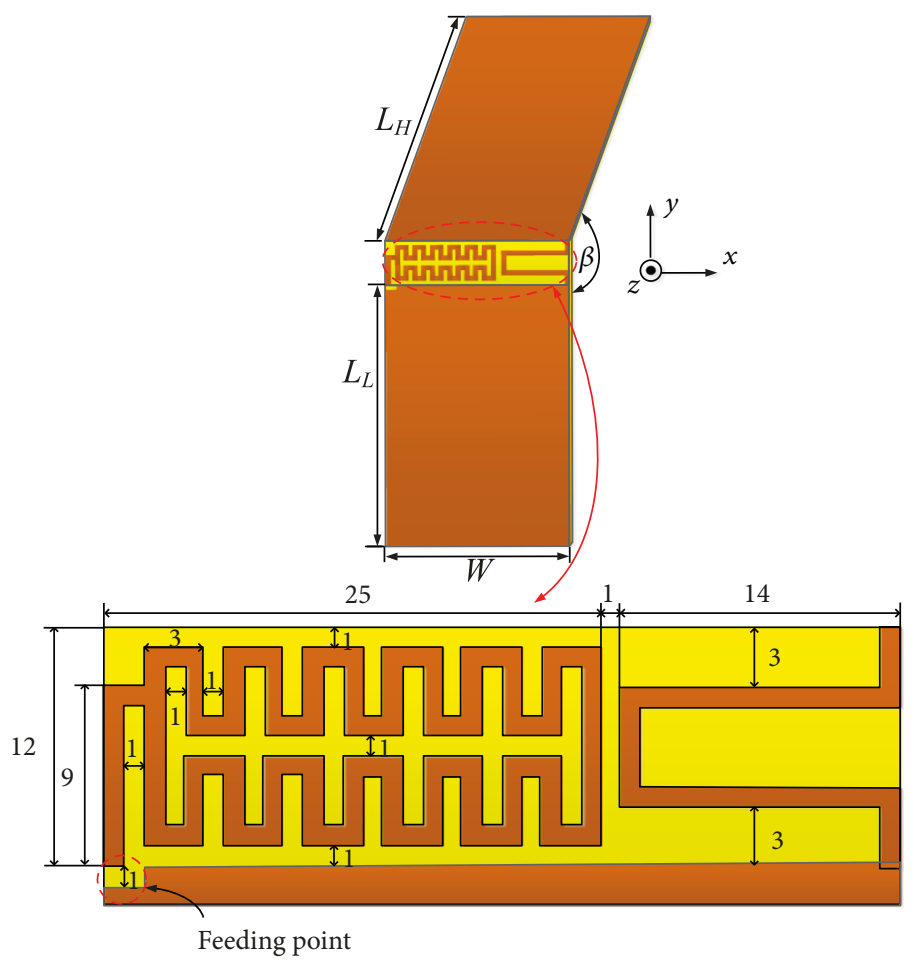

(a)

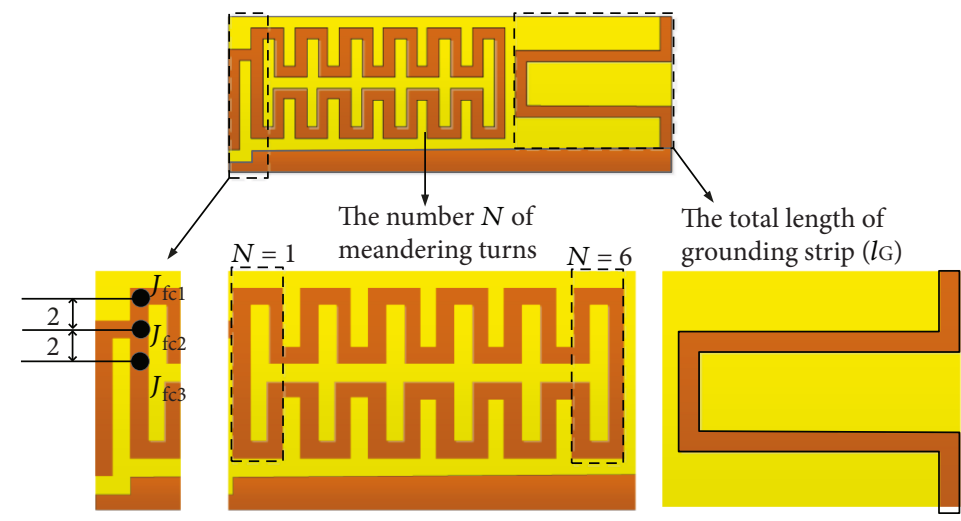

The junction between feeding strip and coupling element $(\mathrm{Jcc})$

(b)

Figure 2: The geometry of the proposed meander line antenna (MLA) without MD (not to scale): (a) the dimensions and (b) the varied parameters $\left(J_{\mathrm{fc}}, N\right.$, and $\left.l_{\mathrm{G}}\right)$ for the optimal impedance bandwidth.

This research used ECCOSORB MF-124 as the MD material. Figure 1 illustrates the simulated real and imaginary (complex) permittivity and permeability of the MD material at the frequency range of $400-1000 \mathrm{MHz}$ using CST Microwave Studio Suite [25]. The ECCOSORB MF-124 in the library of [25] has an average relative permittivity $\left(\varepsilon_{r}\right)$ and permeability $\left(\mu_{r}\right)$ of $22.25-j 0.4$ and $7.05-j 1.24$, respectively. Table 1 tabulates the dielectric loss tangent $\left(\tan \delta_{\varepsilon}=\varepsilon^{\prime \prime} / \varepsilon^{\prime}\right)$ and magnetic loss tangent $\left(\tan \delta_{\mu}=\mu^{\prime \prime} / \mu^{\prime}\right)$ over the target operating band $(470-960 \mathrm{MHz})$.

2.2. Antenna Structure. In this research, the proposed meander line antenna (MLA) [26] attached the lower and upper ground planes of the folder-type chassis, connected electrically using grounding strip. Both ground planes were realized on FR4 substrates whose relative permittivity and loss tangent were 4.4 and 0.02 , respectively. The magneto dielectric material (ECCOSORB MF-124) was subsequently loaded onto the MLA.

Figure 2 depicts the geometry of the proposed MLA in the absence of MD, which was modified from [7]. Accordingly, the initial parameters were as follows: $40 \mathrm{~mm} \times 85 \mathrm{~mm}$ $(L \times W)$ for each of the ground planes; $25 \mathrm{~mm} \times 10 \mathrm{~mm}$ equally for the physical dimension of the MD material (ECCOSORB MF-124) and the coupling element area (the MLA region), where the MD material sits on the MLA region; $155^{\circ}$ for the folder-type chassis angle $(\beta)$; and $1 \mathrm{~mm}$ 


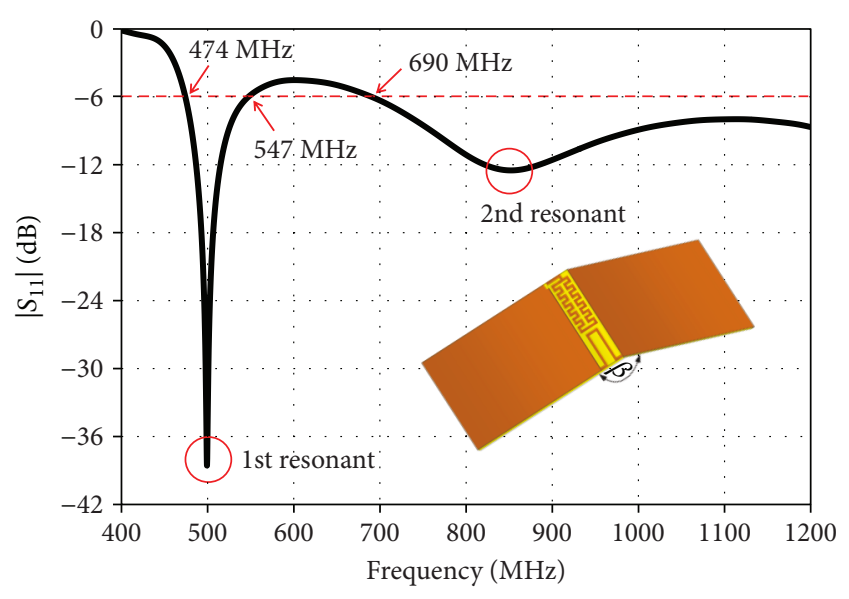

FIGURE 3: Simulated $\left|S_{11}\right|$ of the proposed meander line antenna without MD (non-MD MLA).

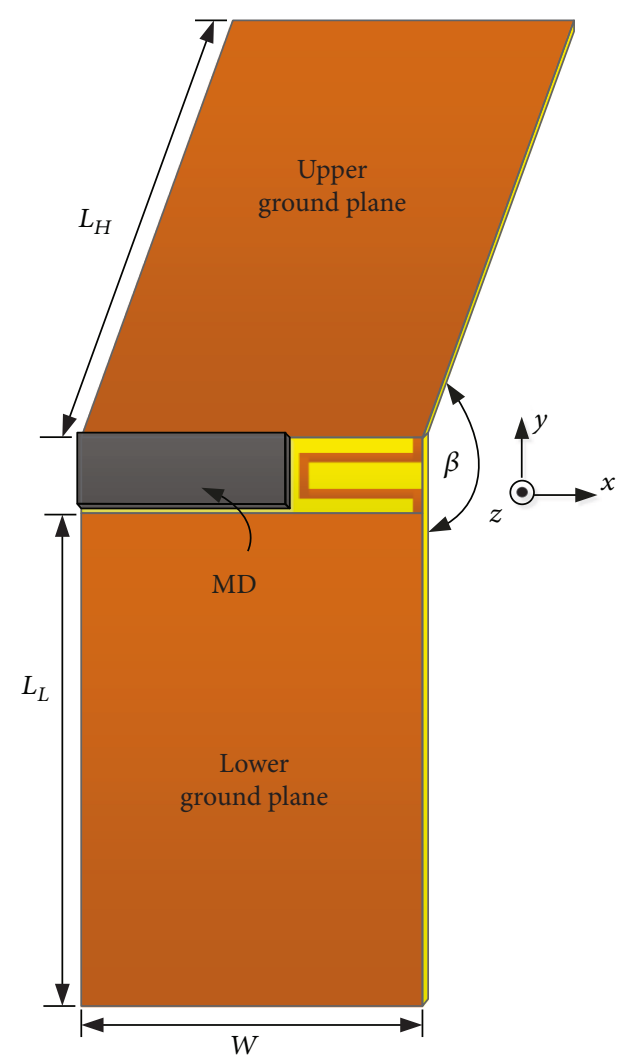

Figure 4: The geometry of the proposed meander line antenna (MLA) with MD (not to scale).

for the width of the strip line for both the coupling element and the grounding strip.

Figure 3 illustrates the simulated $\left|S_{11}\right|$ of the proposed meander line antenna (MLA) without MD relative to frequency $(400-1200 \mathrm{MHz})$. The non-MD MLA achieved two distinct resonant frequencies at $500 \mathrm{MHz}$ and $850 \mathrm{MHz}$. The impedance bandwidth $\left(\left|S_{11}\right|<-6 \mathrm{~dB}\right)$ of the first resonance was narrow $(474-547 \mathrm{MHz})$, while that of the second resonance was very wide $(690 \mathrm{MHz}$ and beyond). In the

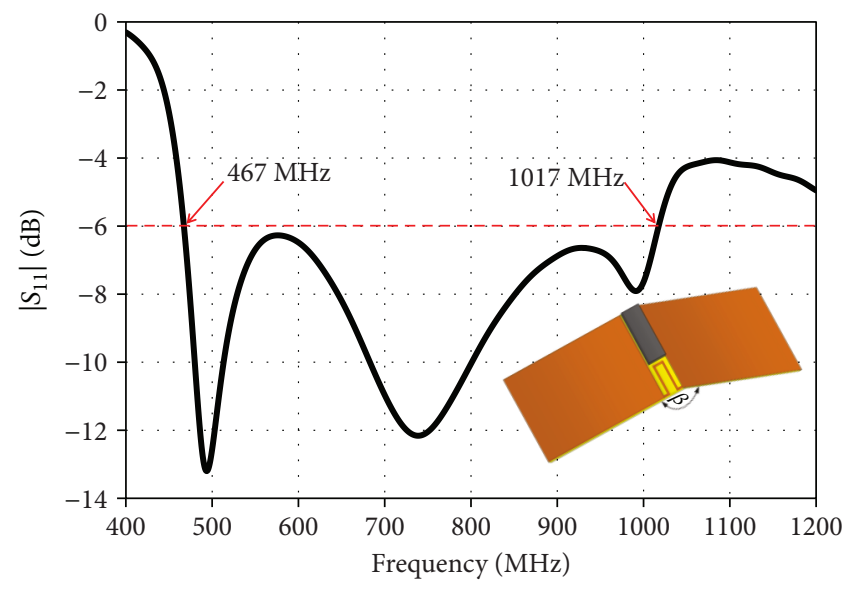

FIgURE 5: Simulated $\left|S_{11}\right|$ of the proposed meander line antenna with MD (MD-laden MLA).

figure, the impedance bandwidth of the non-MD MLA failed to meet the DVB-H/LTE13/GSM850/900 requirements (i.e., $470-960 \mathrm{MHz}$ ). Therefore, the antenna was further refined to achieve the target operating band. More specifically, a magneto dielectric substrate (ECCOSORB MF-124 MD) was loaded onto the MLA region to arrest the impedance bandwidth on the higher-frequency end. Figures 4 and 5, respectively, demonstrate the geometry and the simulated results of the meander line antenna with MD (i.e., the MD-laden MLA).

Figure 5 illustrates the simulated $\left|S_{11}\right|$ of the proposed meander line antenna (MLA) in the presence of MD. The MD-laden MLA achieved a broad impedance bandwidth covering the frequency range of $467-1017 \mathrm{MHz}$, rendering it appropriate for the DVB-H/LTE13/GSM850/900 applications.

The optimal impedance bandwidth of the MD-laden MLA (Figure 5) was achieved using surface current analysis by varying the junction between the feeding strip and the coupling element $\left(J_{\mathrm{fc}}\right)$, the number of meandering turns $(N)$, and the length of the grounding strip $\left(l_{\mathrm{G}}\right)$, in addition to the MD thickness.

2.3. Surface Current Distribution. The surface current analysis of the MD-laden MLA was simulated using CST Microwave Studio Suite at low $(470 \mathrm{MHz})$, center $(685 \mathrm{MHz})$, and high $(900 \mathrm{MHz})$ frequencies of the target operating band. In Figure 6(a), at low frequency, the simulated surface current distribution was bidirectional, similar to that of the conventional dipole antenna. More specifically, the current flowed in two directions. The first direction was from the feeding point to the coupling element, in which the current was initially strong (around the feeding point area) and dissipated as it travelled along the coupling element. The second direction travelled from the feeding point along the upper edge of the lower ground plane through to the grounding strip and the lower edge of the upper ground plane. Thus, the impedance bandwidth at low frequency was largely attributable to the feeding point and the grounding strip, as evidenced by the strong surface current. 

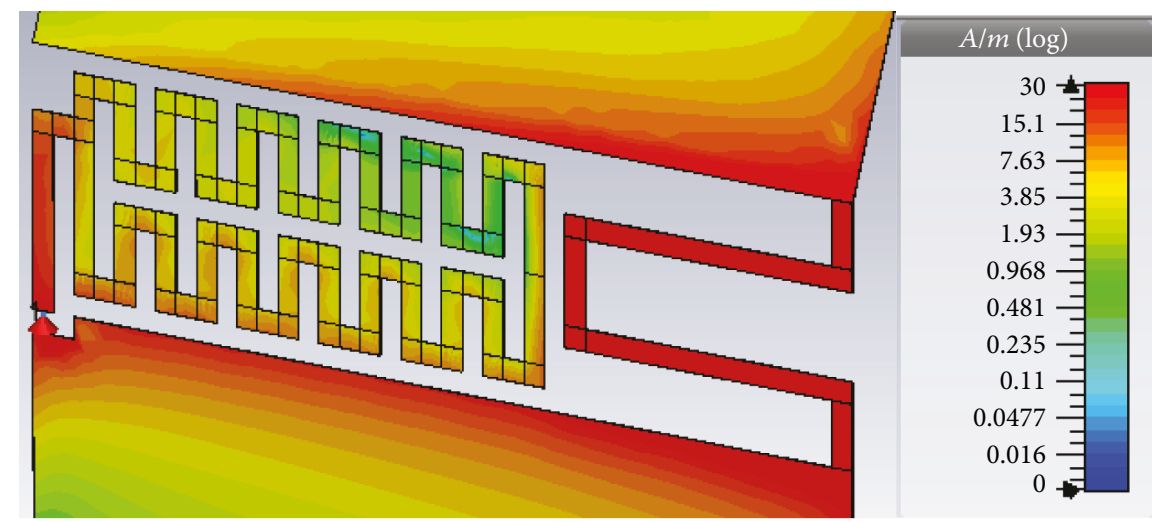

(a) $470 \mathrm{MHz}$
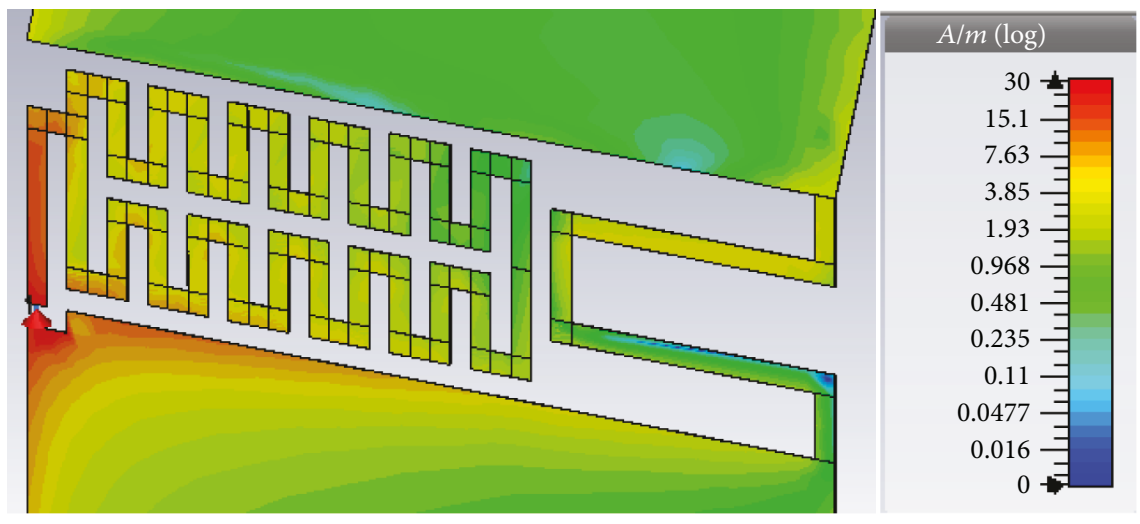

(b) $685 \mathrm{MHz}$

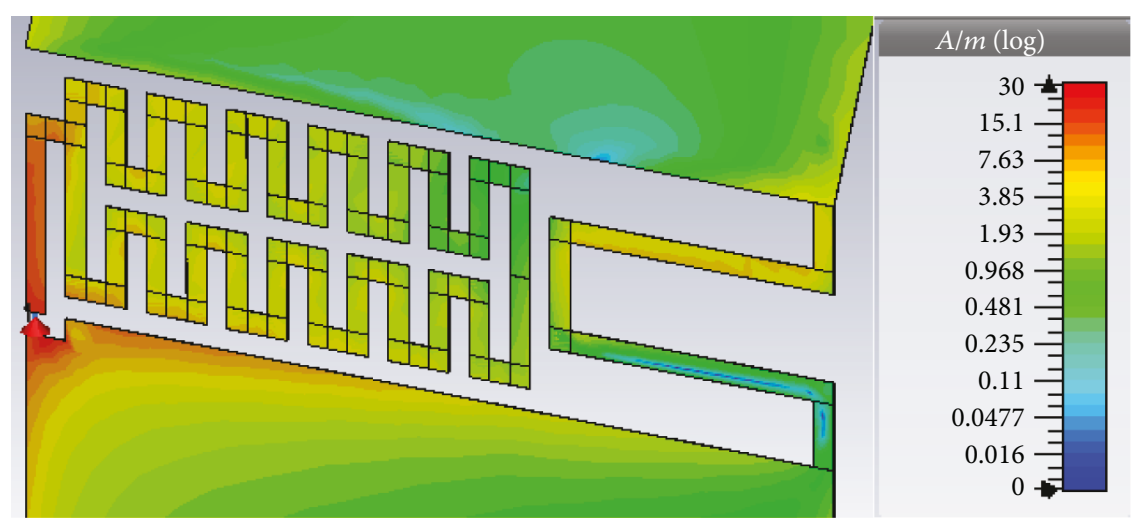

(c) $900 \mathrm{MHz}$

FIgURE 6: Simulated surface current of the MD-loaded MLA at (a) $470 \mathrm{MHz}$, (b) $685 \mathrm{MHz}$, and (c) $900 \mathrm{MHz}$.

At center (Figure 6(b)) and high frequencies (Figure 6(c)), the simulated surface current was strong along the feeding strip and around the upper-left edge of the lower ground plane, resembling that of a dipole antenna along the $y$-axis. Thus, the feeding strip was mainly responsible for the impedance bandwidth at center and high frequencies.

\section{Parametric Study}

The optimal MD-laden MLA was realized by varying the junction between the feeding strip and the coupling element $\left(J_{\mathrm{fc}}\right)$, the length of the grounding strip $\left(l_{\mathrm{G}}\right)$, the number of meandering turns $(N)$, and the MD thickness. The simulations were carried out using CST Microwave Studio Suite.

As previously shown in Figures 6(a)-6(c), the feeding strip played an important role in mediating the impedance bandwidth $\left(\left|S_{11}\right|<-6 \mathrm{~dB}\right)$ at low, center, and high frequencies. However, given the strip line width of $1 \mathrm{~mm}$ [7], the junction between the feeding strip and the coupling element $\left(J_{\mathrm{fc}}\right)$ was instead varied for the optimal joint location.

Figure 7 illustrates the simulated impedance bandwidth $\left(\left|S_{11}\right|\right)$ for variable joint locations $\left(J_{\mathrm{fc} 1}-J_{\mathrm{fc} 3}\right), 2 \mathrm{~mm}$ apart. For $J_{\mathrm{fc} 1}$, the simulated $\left|S_{11}\right|$ was below $-6 \mathrm{~dB}$ in the frequency ranges of $467-565 \mathrm{MHz}$ and $601-1057 \mathrm{MHz}$, partially covering the target operating band $(470-960 \mathrm{MHz})$. For $J_{\mathrm{fc} 2}$ and 


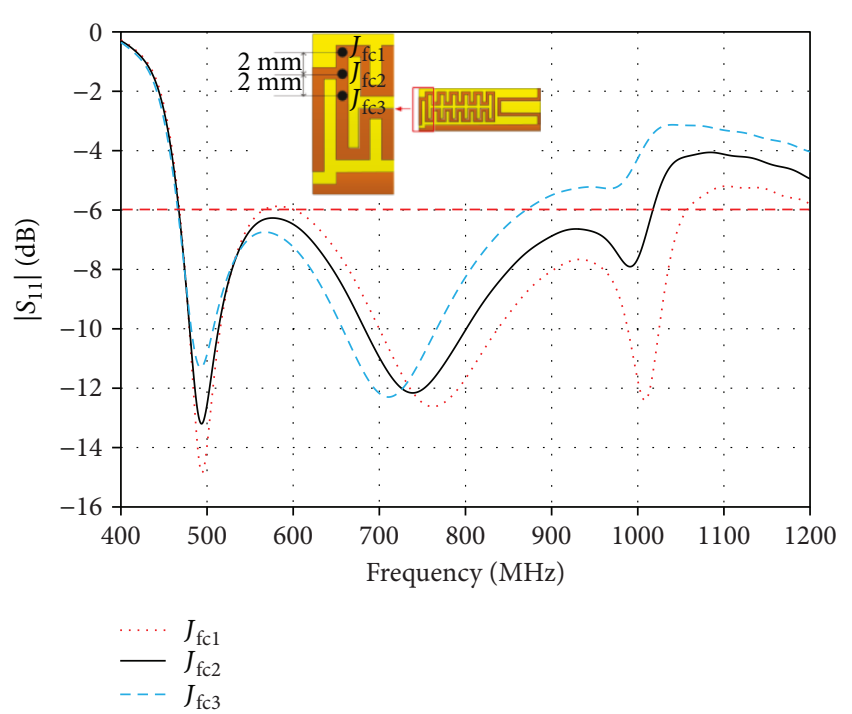

FIGURE 7: Simulated $\left|S_{11}\right|$ of the proposed MD-loaded MLA for variable junctions between the feeding strip and the coupling element $\left(J_{\text {fc }}\right)$.

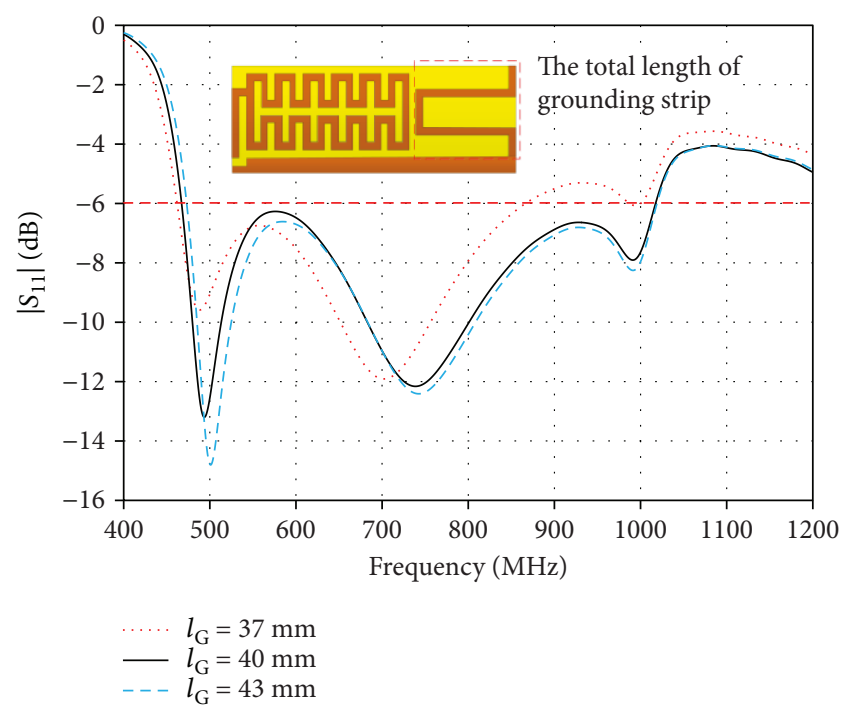

Figure 8: Simulated $\left|S_{11}\right|$ of the proposed MD-loaded MLA for variable grounding strip lengths $\left(l_{\mathrm{G}}\right)$.

$J_{\mathrm{fc} 3}$, the simulated $\left|S_{11}\right|$ was below $-6 \mathrm{~dB}$ from $467-1017 \mathrm{MHz}$ and $466-870 \mathrm{MHz}$, respectively. Thus, $J_{\mathrm{fc} 2}$ was the optimal joint location because of the broader impedance bandwidth, covering the entire target operating band.

As shown in Figure 6(a), the grounding strip played a crucial part in mediating the impedance bandwidth under the lower-frequency condition $(470 \mathrm{MHz})$. Given the strip line width of $1 \mathrm{~mm}$ [7], the ground strip length $\left(l_{\mathrm{G}}\right)$ was varied between 37, 40, and $43 \mathrm{~mm}$. Figure 8 illustrates the simulated $\left|S_{11}\right|$ of the MD-laden MLA under variable $l_{\mathrm{G}}$. With $l_{\mathrm{G}}=37 \mathrm{~mm}$, the simulated $\left|S_{11}\right|$ was below $-6 \mathrm{~dB}$ from 473 to $1019 \mathrm{MHz}$. For $l_{\mathrm{G}}=40$ and $43 \mathrm{~mm}$, the simulated $\left|S_{11}\right|$ below $-6 \mathrm{~dB}$ was realized in the frequency ranges of

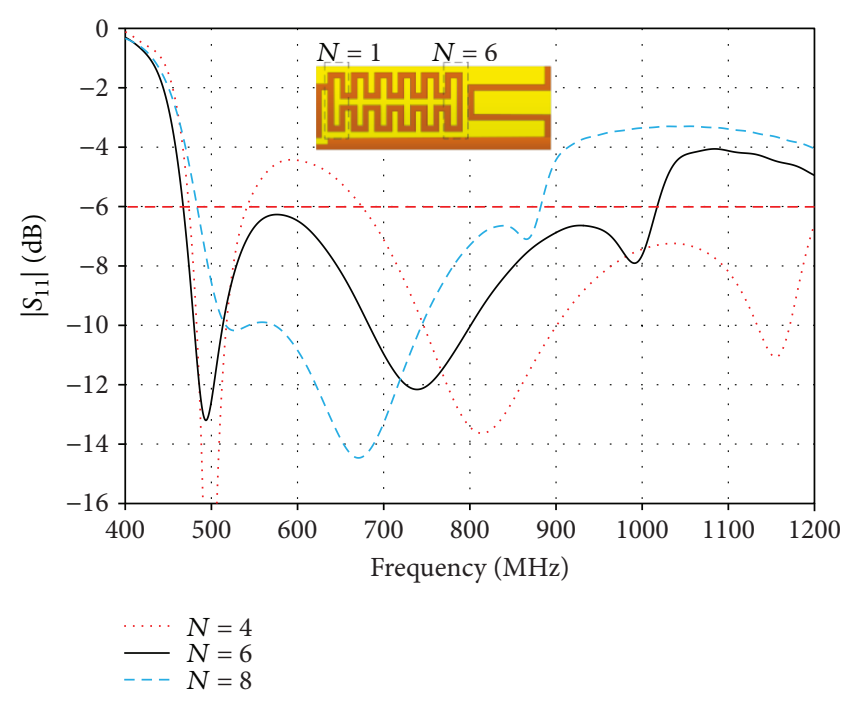

Figure 9: Simulated $\left|S_{11}\right|$ of the proposed MD-loaded MLA for variable numbers of meandering turns $(N)$.

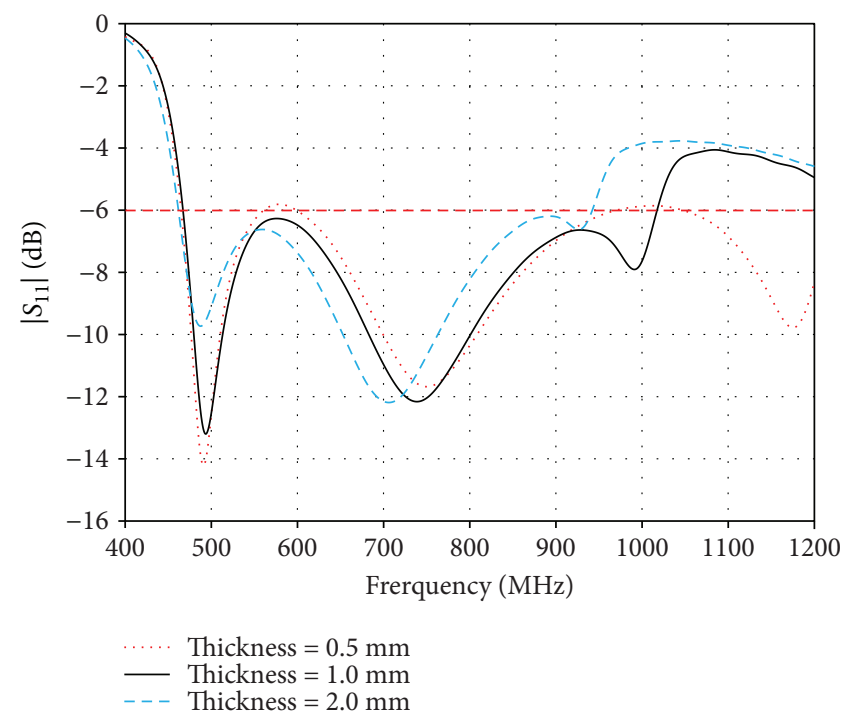

FIgURE 10: Simulated $\left|S_{11}\right|$ of the proposed MD-loaded MLA for variable MD thicknesses.

467-1017 MHz and 462-866 MHz. Given the target operating band of $470-960 \mathrm{MHz}$, the frequency range $(473-1019 \mathrm{MHz})$ of $l_{\mathrm{G}}=37 \mathrm{~mm}$ failed to cover the lower-end frequency of the target band. On the other hand, the frequency range associated with $l_{\mathrm{G}}=43 \mathrm{~mm}(462-866 \mathrm{MHz})$ was considerably short of the higher-end frequency of $960 \mathrm{MHz}$. Meanwhile, the frequency range of $l_{\mathrm{G}}=40 \mathrm{~mm}(467-1017 \mathrm{MHz})$ fully covered the target operating band.

In the MLA, the electrical size of the antenna could be enhanced while maintaining its physical size by varying the number of meandering turns $(N)$. Figure 9 depicts the simulated $\left|S_{11}\right|$ of the MD-laden MLA for variable numbers of meandering turns $(N): 4,6$, and 8 turns. With $N=4$, the simulated $\left|S_{11}\right|$ below $-6 \mathrm{~dB}$ encompassed the frequency ranges 


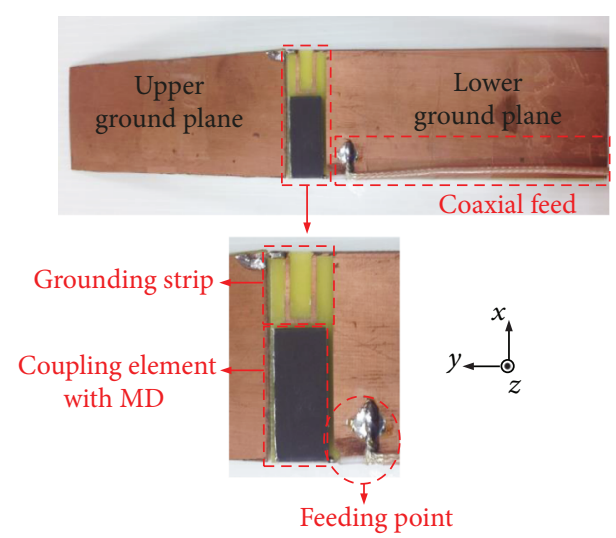

FIgURE 11: Photograph image of the MD-loaded MLA prototype.

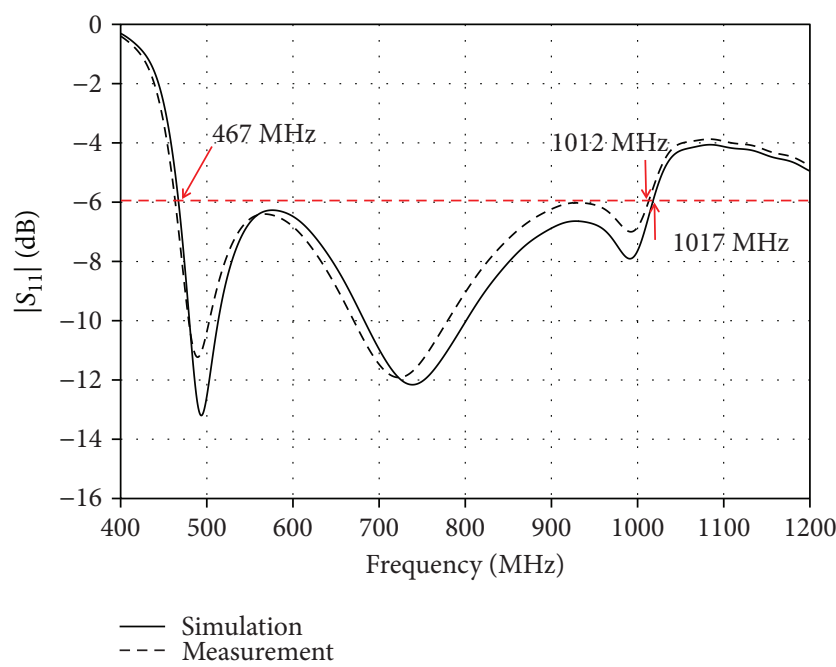

FIGURE 12: The simulated and measured $\left|S_{11}\right|$ of the MD-loaded MLA relative to frequency.

of $457-514 \mathrm{MHz}$ and $677-1200 \mathrm{MHz}$, partially covering the target operating band. With $N=6$ and 8 , the simulated $\left|S_{11}\right|$ below $-6 \mathrm{~dB}$ covered the frequency ranges of 467$1017 \mathrm{MHz}$ and $483-882 \mathrm{MHz}$, respectively. Given the target operating band of $470-960 \mathrm{MHz}$, the optimal number of meandering turns $(N)$ was 6.

Figure 10 illustrates the simulated $\left|S_{11}\right|$ of the MD-laden MLA for variable MD thicknesses: $0.5,1$, and $1.5 \mathrm{~mm}$. With $0.5 \mathrm{~mm}$ thickness, the simulated $\left|S_{11}\right|$ below $-6 \mathrm{~dB}$ spanned the frequency ranges of $464-561 \mathrm{MHz}$ and $600-970 \mathrm{MHz}$, partially covering the target operating band. With the thickness of 1 and $2 \mathrm{~mm}$, the simulated $\left|S_{11}\right|$ below $-6 \mathrm{~dB}$ covered the frequency ranges of $467-1017 \mathrm{MHz}$ and $461-942 \mathrm{MHz}$, respectively. The optimal $\mathrm{MD}$ thickness of $1 \mathrm{~mm}$ exhibited the best impedance matching.

\section{Antenna Prototype and Measured Results}

To verify the simulation results, a prototype antenna was fabricated and the experimental results were measured, as shown in Figure 11. Figure 12 compares the simulated and experimental $\left|S_{11}\right|$ of the proposed MD-laden MLA, in which the corresponding impedance bandwidths $\left(\left|S_{11}\right|<-6 \mathrm{~dB}\right)$ covered the frequency ranges of $467-1017 \mathrm{MHz}(74.12 \%)$ and $467 \mathrm{MHz}-1012 \mathrm{MHz}$ (73.6\%). The simulation and experimental results were in good agreement.

The measurement setup uses identical transmitting and receiving antennas. The transmission between antennas was measured using network analyzer model Agilent E5061B carried out in the anechoic chamber. To evaluate the radiation characteristics, the radiation patterns were measured in three principal planes ( $x z, y z$, and $x y$ planes). The tested antennas are separated by the distance of the far-field region. Meanwhile, the bore sight gain was measured based on the Friis transmission formula that can be accomplished by swept frequency. Figures 13(a)-13(f), respectively, illustrate the simulated and measured $x z, y z$, and $x y$ plane radiation patterns of the MD-laden MLA at 470, 666, 766, 850, 862, and $900 \mathrm{MHz}$. The proposed MD-laden antenna exhibited an omnidirectional radiation pattern over the experimental frequency band (470-900 MHz). The maximum simulated and experimental cross polarizations (x-pol) were approximately $-10 \mathrm{~dB}$ for the $x z, y z$, and $x y$ planes across the experimental frequency band. The simulated and measured half-power beamwidths (HPBW) of the $y z$ and $x y$ planes were $79.2^{\circ}-$ $88.2^{\circ}$ and $73^{\circ}-85.8^{\circ}$, respectively. Despite the cross polarization, the radiation pattern of the MD-laden antenna was omnidirectional, rendering it suitable for DVB-H/LTE13/ GSM850/900 applications.

In Figure 14, the minimum and maximum simulated gains were 0.86 and $1.65 \mathrm{dBi}$, which were agreeable with the corresponding measured gains of 0.65 and $1.54 \mathrm{dBi}$. The simulated radiation and total efficiencies of the MDladen MLA were 91.7-95.6\% and 69.9-85.5\%, respectively. Table 2 tabulates the $x y$ and $y z$ plane HPBW, gains, radiation, and total efficiencies.

\section{Conclusion}

This research has proposed a miniaturized meander line antenna (MLA) using a magneto dielectric (MD) material for mobile device applications. The proposed MD-laden MLA attached the lower and upper ground planes of the folder-type chassis, connected electrically using a grounding strip. The MD material (ECCOSORB MF-124) was subsequently loaded onto the coupling element area of the MLA. The antenna was ultracompact $(10 \mathrm{~mm} \times 25 \mathrm{~mm} \times 1 \mathrm{~mm})$, with the electrical size of $0.015 \lambda \times 0.039 \lambda \times 0.0015 \lambda$ at $470 \mathrm{MHz}$. The surface current distribution was simulated to determine the optimal parameters of the MD-laden MLA: the junction between the feeding strip and the coupling element, the length of the grounding strip, and the number of meandering turns, in addition to the MD thickness. To verify, a prototype MD-laden MLA was fabricated and the experiment was carried out. The measured impedance bandwidth $\left(\left|S_{11}\right|<-6 \mathrm{~dB}\right)$ covered the frequency range of $467-$ $1012 \mathrm{MHz}(73.6 \%)$, covering the entire target operating band (470-960 MHz). The radiation pattern was omnidirectional, with the antenna's radiation efficiency in excess of $90 \%$, 


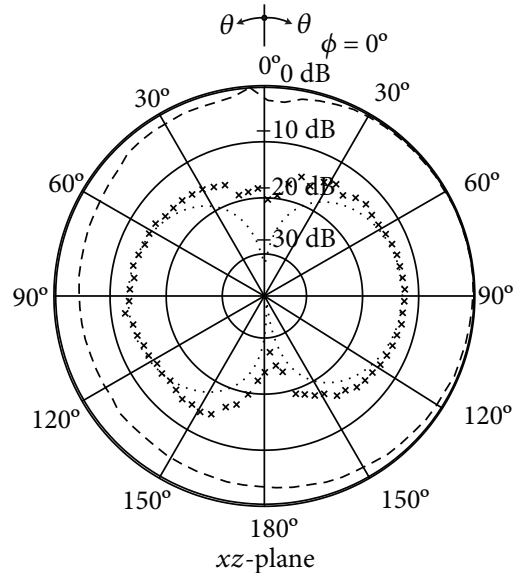

$\begin{array}{ll} & \text { Simulated co-pol } \\ \ldots \ldots & \text { Simulated } \mathrm{x} \text {-pol }\end{array}$

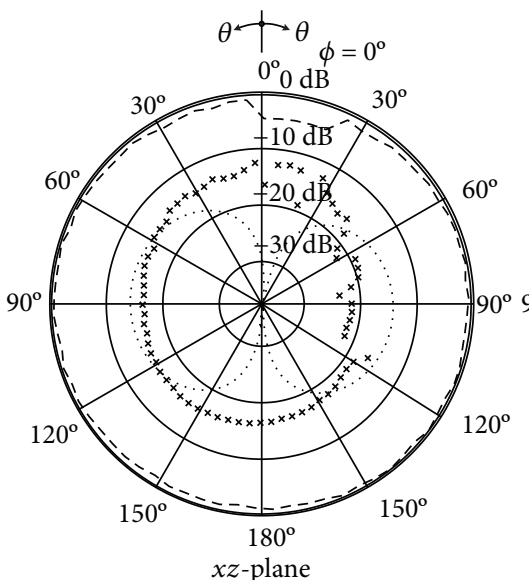

Simulated co-pol Simulated x-pol

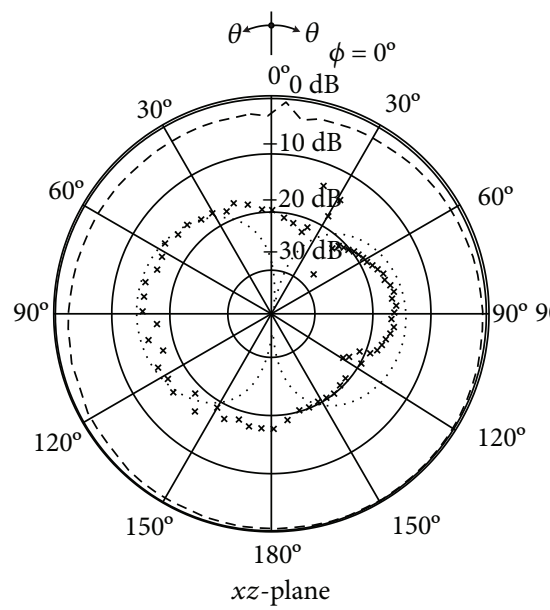

Simulated co-pol Simulated x-pol

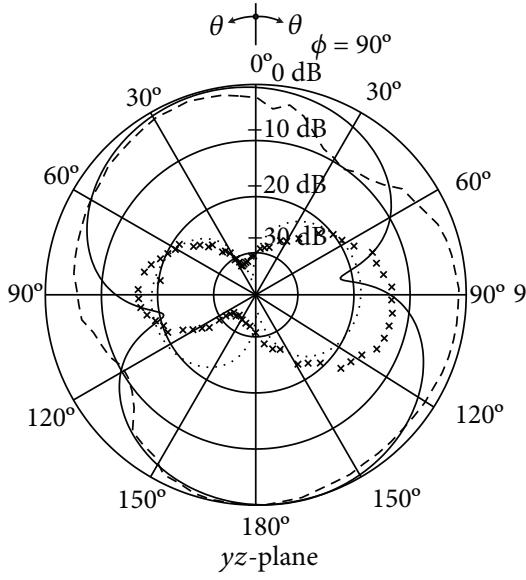

---- Measured co-pol

$x \times x \times x$ Measured $x-p o l$

(a) $470 \mathrm{MHz}$

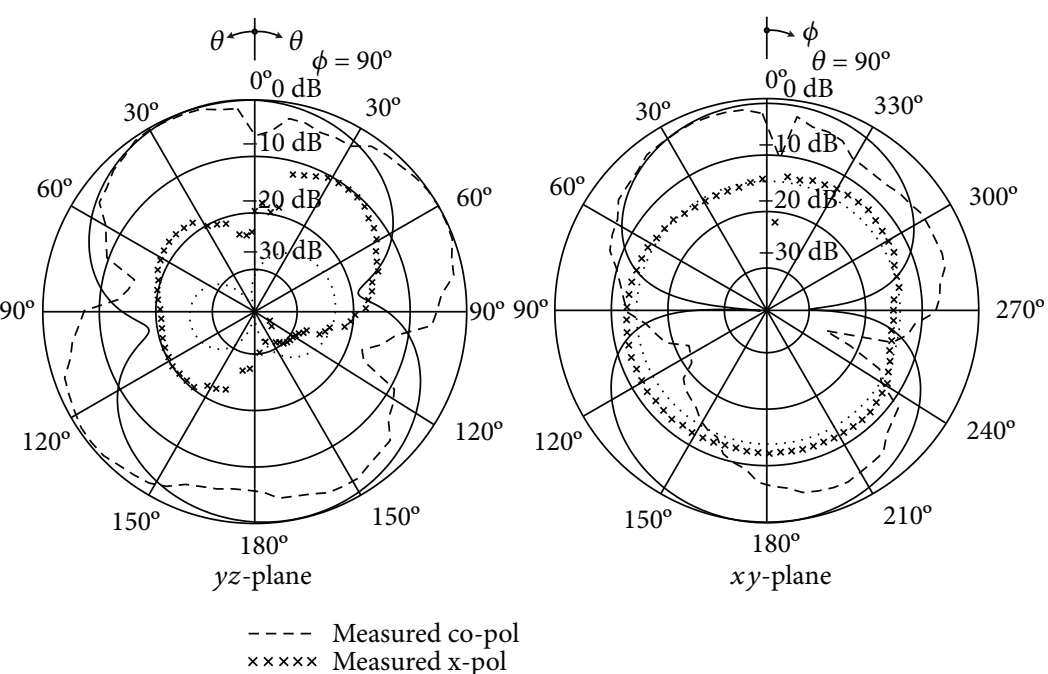

(b) $666 \mathrm{MHz}$

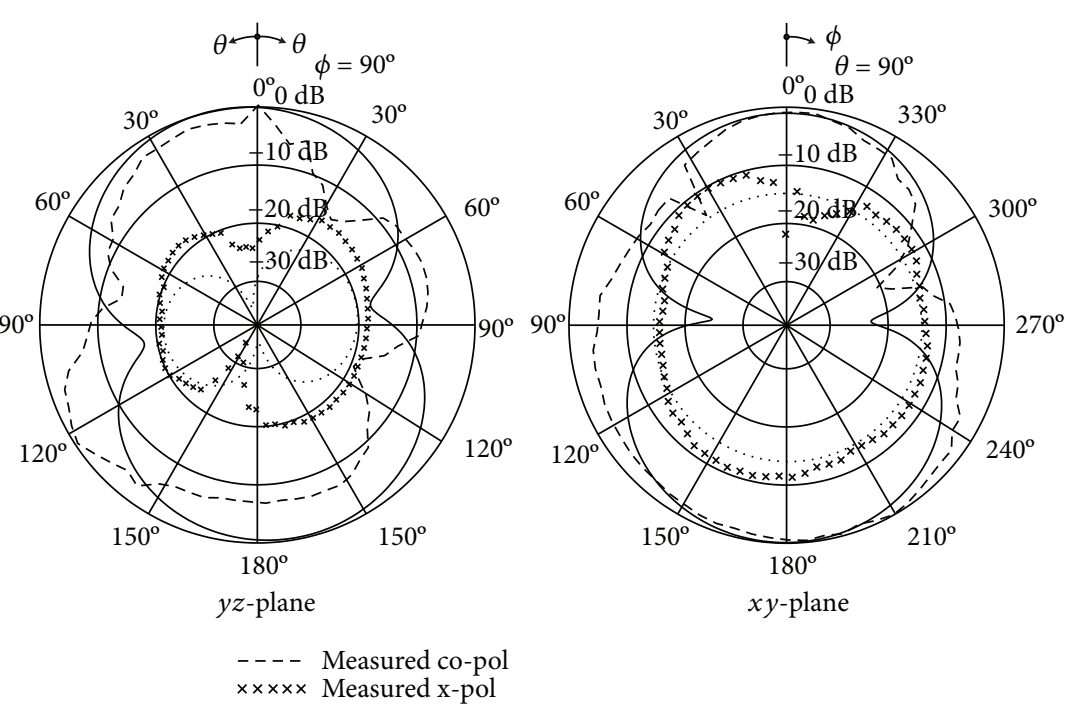

(c) $766 \mathrm{MHz}$

Figure 13: Continued.
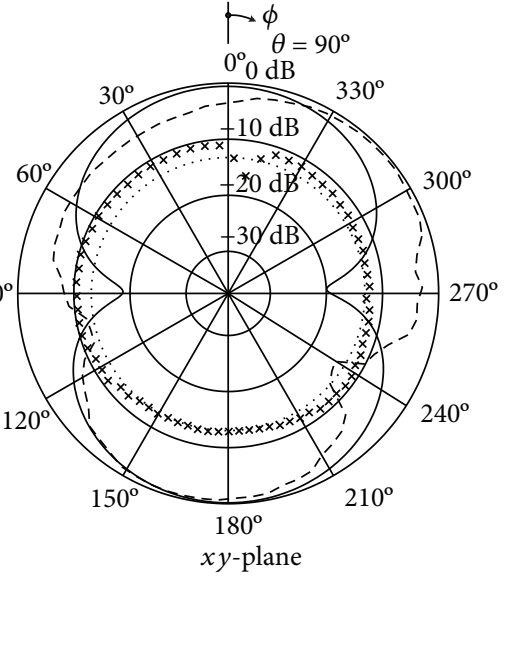


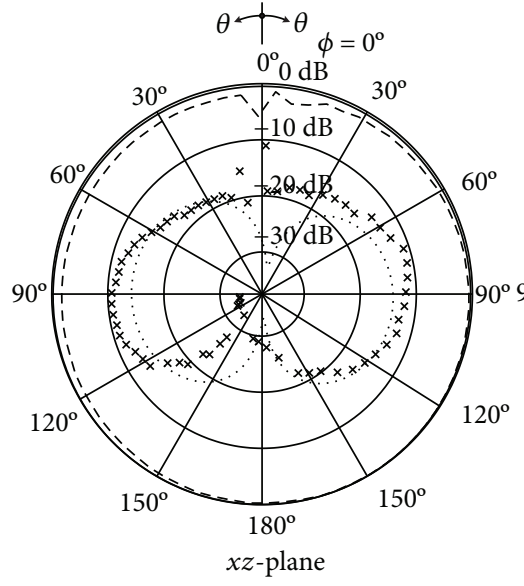

- Simulated co-pol Simulated $\mathrm{x}$-pol

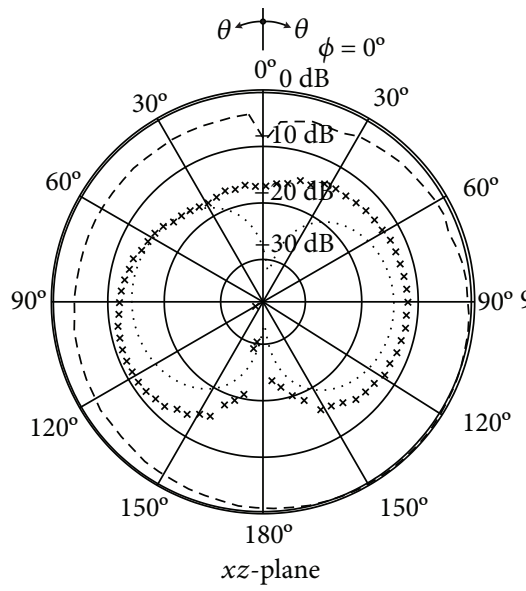

Simulated co-pol Simulated x-pol

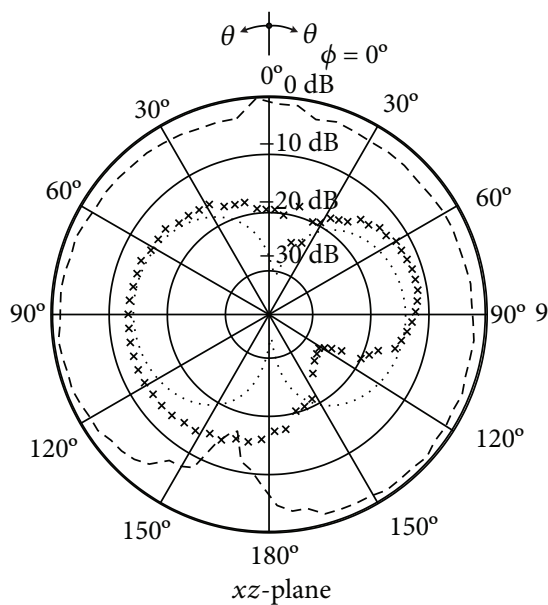

Simulated co-pol Simulated x-pol

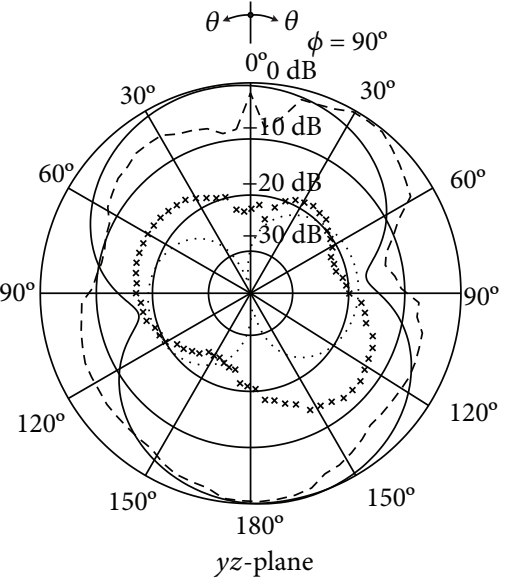

-- -- Measured co-pol

$x \times x \times x$ Measured $x-p o l$

(d) $850 \mathrm{MHz}$

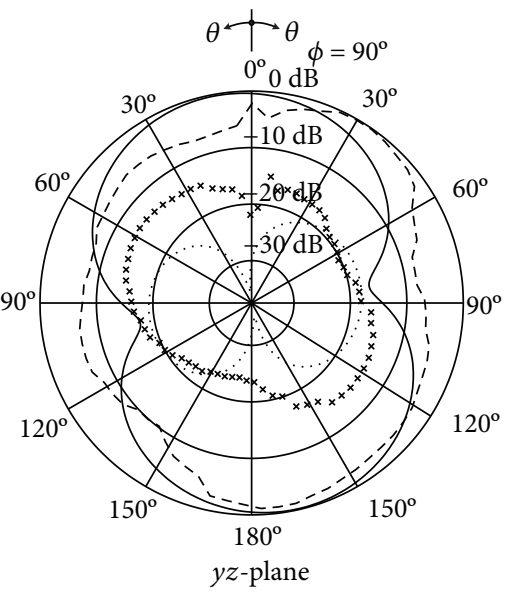

- - - Measured co-pol

$x \times x \times x$ Measured $x-p o l$

(e) $862 \mathrm{MHz}$

$\theta \uparrow_{\phi=90^{\circ}}$
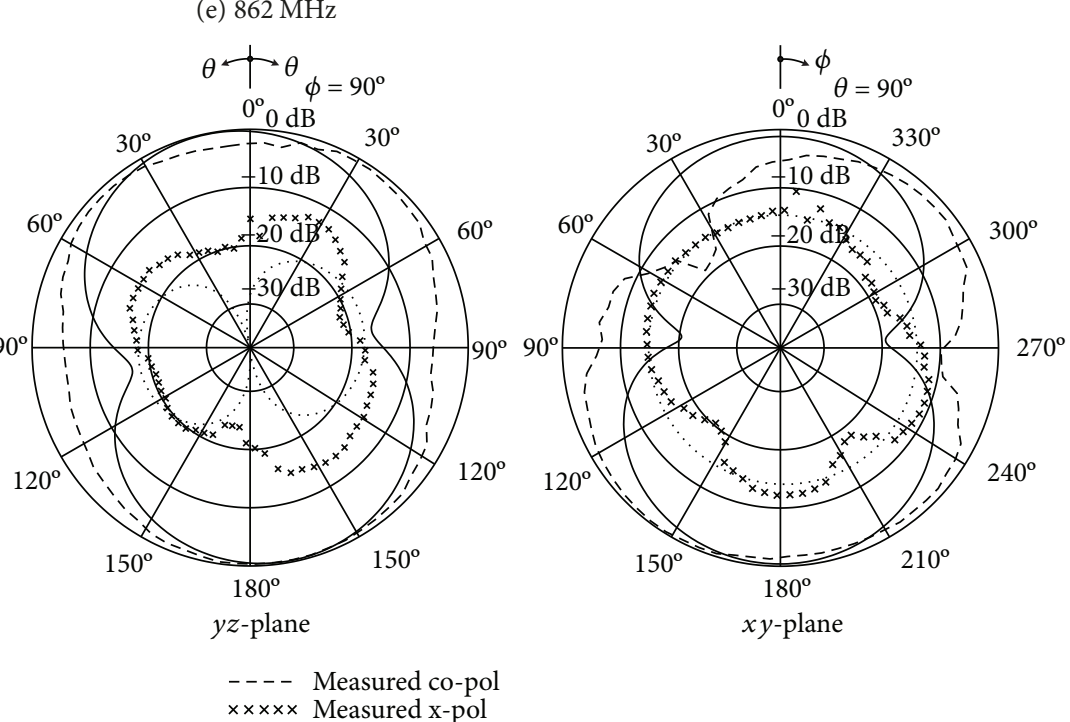

- - - Measured co-pol

$x \times x \times x$ Measured $x-p o l$

(f) $900 \mathrm{MHz}$
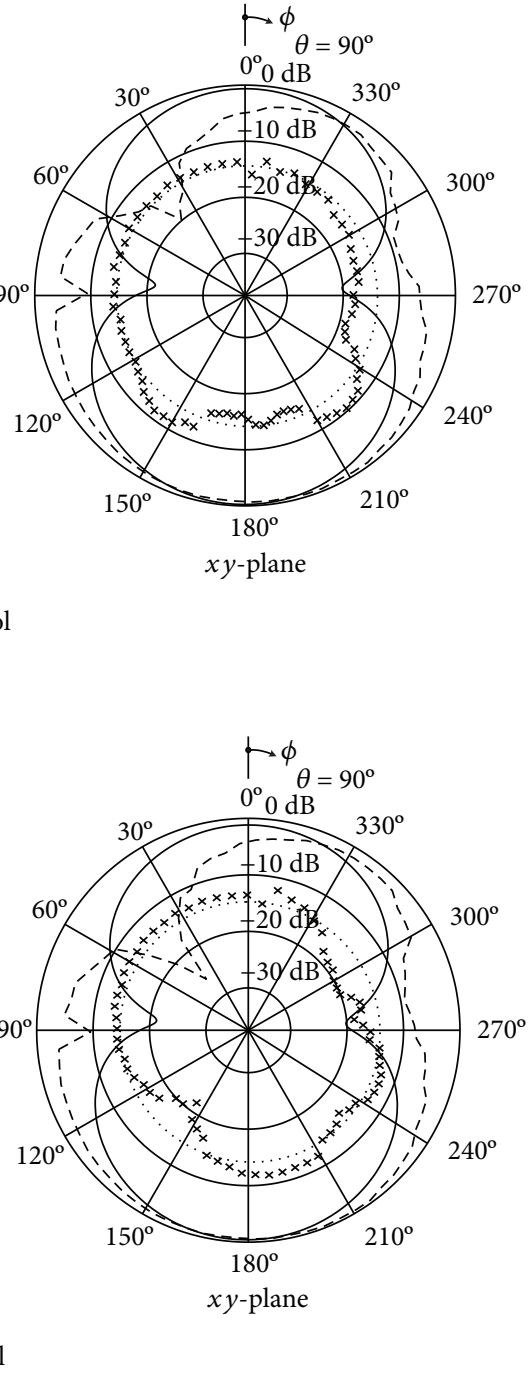

Figure 13: The simulated and measured radiation patterns of the MD-loaded MLA: (a) $470 \mathrm{MHz}$, (b) $666 \mathrm{MHz}$, (c) $766 \mathrm{MHz},(\mathrm{d}) 850 \mathrm{MHz}$, (e) $862 \mathrm{MHz}$, and (f) $900 \mathrm{MHz}$. 


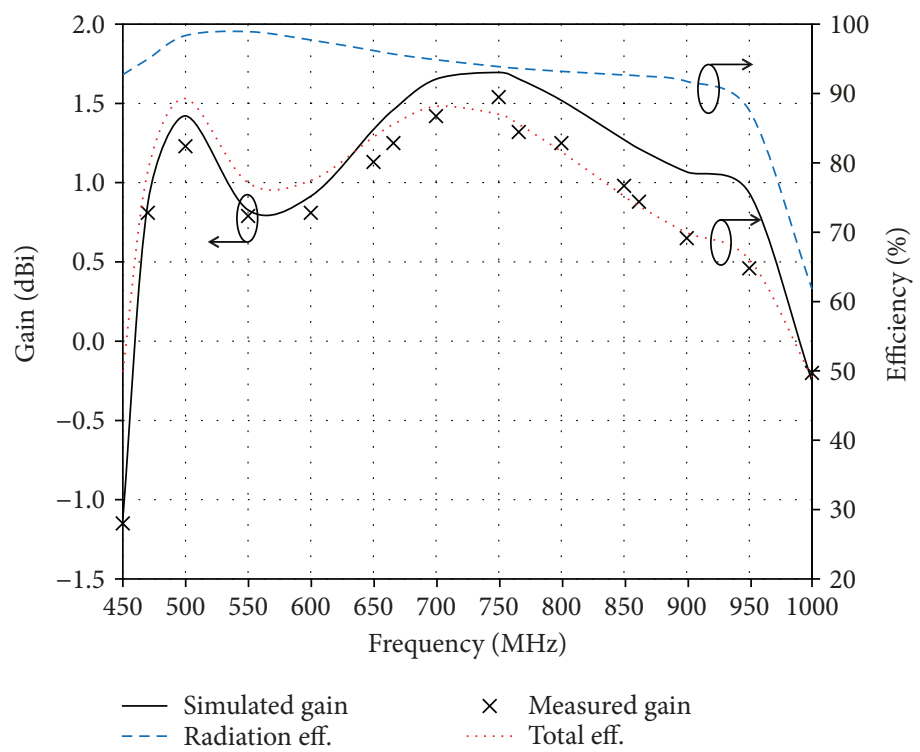

FIGURE 14: The simulated radiation and total efficiencies and simulated and measured gains of the MD-loaded MLA.

TABLE 2: The radiation performance of the proposed MD-loaded MLA.

\begin{tabular}{lccccc}
\hline $\begin{array}{l}\text { Frequency } \\
(\mathrm{MHz})\end{array}$ & $\begin{array}{c}\text { HPBW of } x \\
y \text { plane }\left(^{\circ}\right)\end{array}$ & $\begin{array}{c}\text { HPBW of } \\
y z \text { plane }\left(^{\circ}\right)\end{array}$ & $\begin{array}{c}\text { Gain } \\
(\mathrm{dBi})\end{array}$ & $\begin{array}{c}\text { Radiation } \\
\text { eff. }(\%)\end{array}$ & $\begin{array}{c}\text { Total } \\
\text { eff. } \\
(\%)\end{array}$ \\
\hline 470 & 85.8 & 88.2 & 0.86 & 94.9 & 78.8 \\
666 & 81.1 & 84.6 & 1.46 & 95.6 & 85.5 \\
766 & 79.9 & 82.5 & 1.65 & 93.6 & 85.5 \\
850 & 74.9 & 80.5 & 1.27 & 92.6 & 75.1 \\
862 & 74.4 & 80.2 & 1.21 & 92.5 & 73.7 \\
900 & 73 & 79.2 & 1.06 & 91.7 & 69.9 \\
\hline
\end{tabular}

rendering it appropriate for the DVB-H/LTE13/GSM850/ 900 applications. The principal advantage of the MD-laden MLA lies in its ultracompact size and thereby can be readily integrated in the small mobile devices.

\section{Data Availability}

The data used to support the findings of this study are available from the corresponding author upon request.

\section{Conflicts of Interest}

The authors declare that there is no conflict of interests regarding the publication of this paper.

\section{Acknowledgments}

This work has been supported by the Thailand Research Fund through the Research Grant for New Scholar Program under Grant no. MRG6080146. The authors acknowledge with gratefulness the resources provided by the Institute of
Research and Development, Rajamangala University of Technology Rattanakosin.

\section{References}

[1] P. Lindberg and A. Kaikkonen, "Earpiece cord antenna for DVB-H reception in wireless terminals," Electronics Letters, vol. 42, no. 11, pp. 609-611, 2006.

[2] K. R. Boyle and P. J. Massey, "Nine-band antenna system for mobile phones," Electronics Letters, vol. 42, no. 5, pp. 265-266, 2006.

[3] J. Kim, G. Kim, W. Seong, and J. Choi, "A tunable internal antenna with an epsilon negative zeroth order resonator for DVB-H service," IEEE Transactions on Antennas and Propagation, vol. 57, no. 12, pp. 4014-4017, 2009.

[4] L. Liu, J. Rigelsford, and R. Langley, "Tunable multiband handset antenna operating at VHF and UHF bands," IEEE Transactions on Antennas and Propagation, vol. 61, no. 7, pp. 3790-3796, 2013.

[5] L. Huitema, T. Reveyrand, J.-L. Matteiand, E. Arnaud, C. Decroze, and T. Monediere, "Frequency tunable antenna using a magneto-dielectric material for DVB-H application," IEEE Transactions on Antennas and Propagation, vol. 61, no. 9, pp. 4456-4466, 2013.

[6] D. H. Chio, H. S. Yun, and S. O. Park, "Internal antenna with modified monopole type for DVB-H applications," Electronics Letters, vol. 42, no. 25, pp. 1436-1438, 2006.

[7] H. Rhyu, C. Jung, J. Byun et al., "DVB-H antenna design using folder-type chassis and coupling element on a ferrite," IEEE Antennas and Wireless Propagation Letters, vol. 8, pp. 453456, 2009.

[8] S. Jeon, Y. Liu, S. Ju, and H. Kim, "PIFA with parallel resonance feed structure for wideband operation," Electronics Letters, vol. 47, no. 23, pp. 1263-1265, 2011.

[9] Z. Zhang, Antenna Design for Mobile Devices, John Wiley \& Sons (Asia) Pte Ltd-IEEE Press, 2011.

[10] S.-L. Zuo, Z.-Y. Zhang, and J.-W. Yang, "Planar meander monopole antenna with parasitic strips and sleeve feed for 
DVB-H/LTE/GSM850/900 operation in the mobile phone," IEEE Antennas and Wireless Propagation Letters, vol. 12, pp. 27-30, 2013.

[11] R. C. Hansen and M. Burke, "Antennas with magneto-dielectrics," Microwave and Optical Technology Letters, vol. 26, no. 2, pp. 75-78, 2000.

[12] H. Mosallaei and K. Sarabandi, "Magneto-dielectrics in electromagnetics: concept and applications," IEEE Transactions on Antennas and Propagation, vol. 52, no. 6, pp. 1558-1567, 2004.

[13] P. M. T. Ikonen, K. N. Rozanov, A. V. Osipov, P. Alitalo, and S. A. Tretyakov, "Magnetodielectric substrates in antenna miniaturization: Potential and limitations," IEEE Transactions on Antennas and Propagation, vol. 54, no. 11, pp. 3391-3399, 2006.

[14] B. Kim, H. Rhyu, I. Y. Lee, J. Byun, and B. Lee, "Compact internal antenna using a ferrite material for DVB-H reception in mobile phone," in 2008 IEEE Antennas and Propagation Society International Symposium, pp. 1-4, San Diego, CA, USA, July 2008.

[15] C. H. Park, H. Rhyu, S. H. Kim, C. Jung, and B. Lee, "Internal DTV antenna on multilayered ferrite substrate for mobile phone applications," in 2008 IEEE Antennas and Propagation Society International Symposium, pp. 1-4, San Diego, CA, USA, July 2008.

[16] J. F. Pintos, A. Louzir, P. Minard et al., "Ultra-miniature UHF antenna using magneto-dielectric material," in 2010 14th International Symposium on Antenna Technology and Applied Electromagnetics \& the American Electromagnetics Conference (ANTEM-AMEREM), vol. 5-8, pp. 1-4, Ottawa, ON, Canada, July 2010.

[17] C. Niamien, S. Collardey, A. Sharaiha, and K. Mahdjoubi, "Compact expressions for efficiency and bandwidth of patch antennas over lossy magneto-dielectric materials," IEEE Antennas and Wireless Propagation Letters, vol. 10, pp. 63-66, 2011.

[18] F. Ferrero, A. Chevalier, J. M. Ribero, R. Staraj, J. L. Mattei, and Y. Queffelec, "A new magneto-dielectric material loaded, tunable UHF antenna for handheld devices," IEEE Antennas and Wireless Propagation Letters, vol. 10, pp. 951-954, 2011.

[19] C. Caloz and T. Itoh, Electromagnetic Metamaterials, Transmission Line Theory and Microwave Applications, Wiley-IEEE Press, 2005.

[20] G. V. Eleftheriades and K. G. Balmain, Negative Refraction Metamaterials: Fundamental Principles and Applications, Wiley-IEEE Press, 2005.

[21] N. Engheta and R. W. Ziolkowski, Electromagnetic Metamaterials: Physics and Engineering Explorations, Wiley-IEEE Press, 2006.

[22] R. R. Marqués, F. Martín, and M. Sorolla, Metamaterials with Negative Parameters: Theory, Design and Microwave Applications, Wiley Interscience, 2008.

[23] L. Solymar and E. Shamonina, Waves in Metamaterials, Oxford University Press, Oxford, 2009.

[24] ECCOSORB ${ }^{\circledR} \mathrm{MF}$, “Emersion \& Cuming Microwave products website," http://www.eccosorb.com/products.

[25] CST Microwave Studio Suite (User's Manual), 2006.

[26] F. Kyohei and M. Hisashi, Modern Small Antennas: First published, chapter 7, United States of America by Cambridge University Press, New York, 2013, Cambridge University Press is part of the University of Cambridge. 


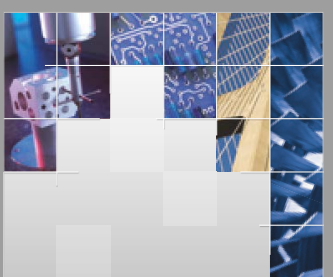

\section{Enfincering}
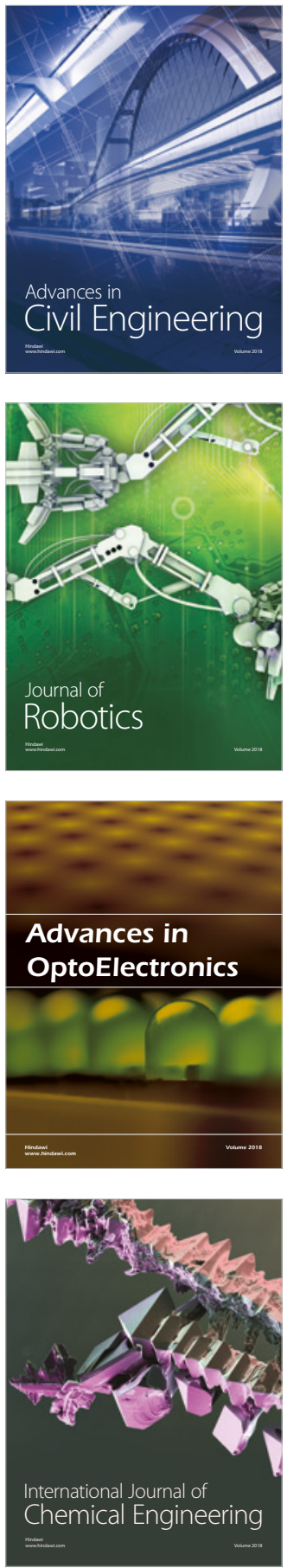

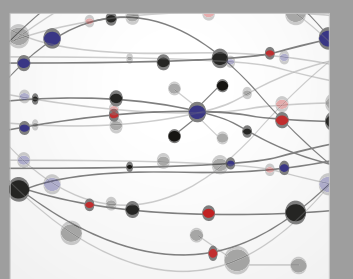

\section{Rotating \\ Machinery}

The Scientific World Journal

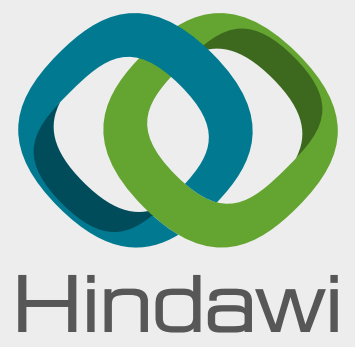

Submit your manuscripts at

www.hindawi.com
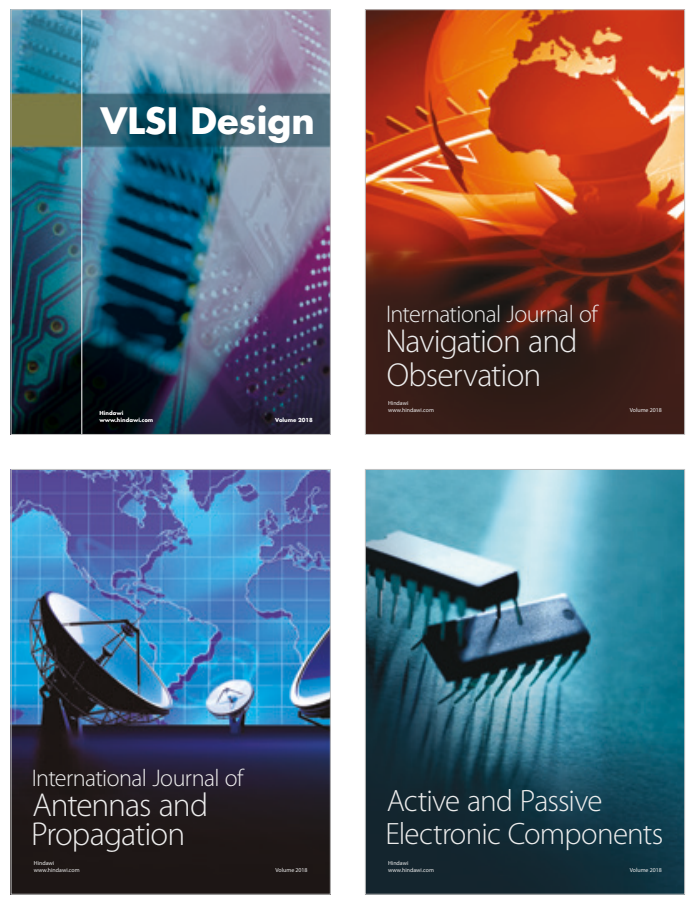
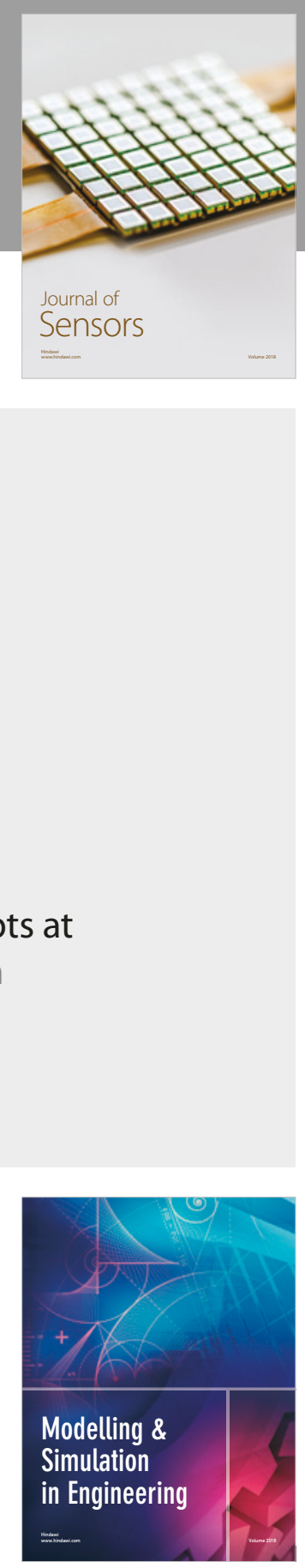

\section{Advances \\ Multimedia}
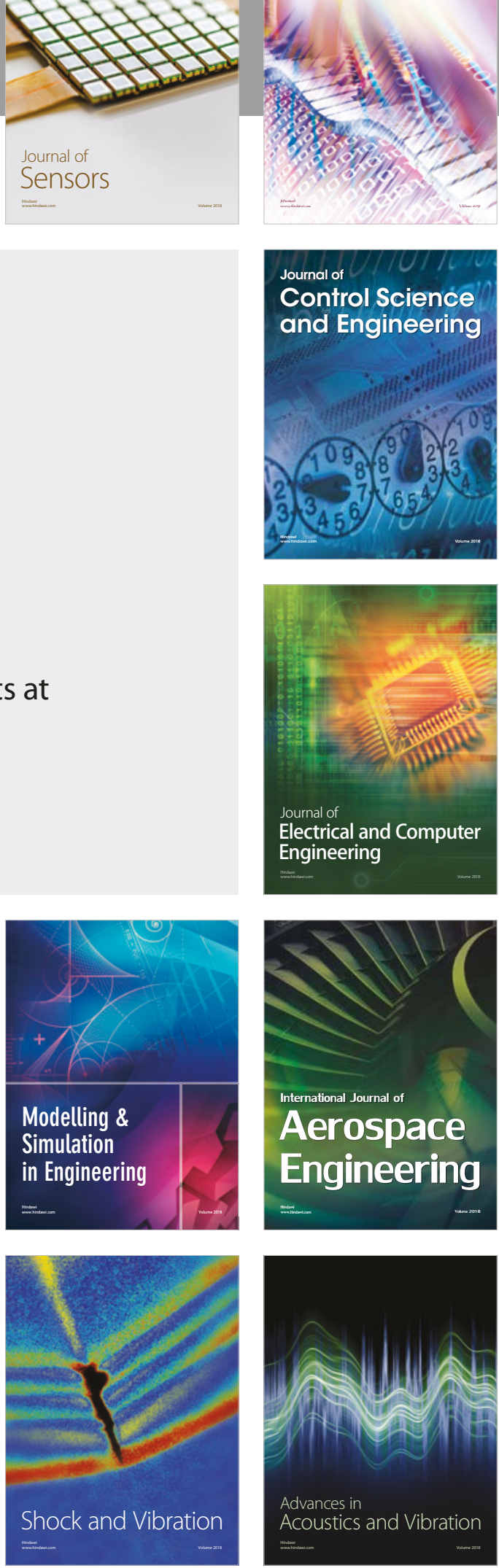